\title{
Changes in systolic time intervals during treatment of diabetes mellitus
}

\author{
C. A. SYKES, ${ }^{1}$ A. D. WRIGHT, J. M. MALINS, AND B. L. PENTECOST \\ From the General Hospital, Birmingham
}

The cardiovascular response to the control of diabetes by sulphonylurea drugs has been investigated using systolic time intervals in a group of 19 diabetics. Before treatment a significantly greater heart rate and shortening of $Q S_{2}$ interval and left ventricular ejection time index were encountered among the more hyperglycaemic diabetic patients requiring drug therapy while all diabetics had a reduction of pre-ejection period index. There was a gradual return of resting heart rate and systolic time intervals to control values along with the fall in plasma sugar concentration during treatment. A likely explanation of the findings is that uncontrolled diabetics, particularly those more severely affected, are subjected to an increased adrenergic stimulus to the cardiovascular system which disappears with therapy. There is no evidence of positive inotropic action of sulphonylurea drugs in this study.

Since the publication of the University Group Diabetes Programme (Klimt et al., 1970) which suggested an increase in mortality from cardiovascular disorders in those patients treated with tolbutamide, several workers have studied the effects of this drug on the heart in vivo and in vitro. The results have been confusing. Some authors have reported a positive inotropic effect (Hildner et al., 1971; Palmer et al., 1971; Lasseter et al., 1972; Young et al., 1975), while Crass et al. (1973) have shown that increased contractility is dose dependent and that above a certain concentration of tolbutamide negative inotropism results. Crockett et al. $(1973,1974)$ could not show any inotropic effect on the human heart in clinical studies despite increased contractility of both animal and human hearts in vitro. The majority of these were acute studies after parenteral administration of the drug.

In an attempt to resolve this conflict it was decided to examine changes in myocardial function during the first three months' treatment of diabetes. Two groups of diabetic patients were studied, one managed by diet and the other treated with diet and a sulphonylurea drug. Simultaneous recordings of the electrocardiogram, phonocardiogram, and carotid pulse were performed in order to obtain systolic time intervals (Weissler et al., 1969). This technique has been used to study changes in myocardial contractility produced by cardiac glycosides, adrenergic 'Present address: Sefton General Hospital, Smithdown Road, Liverpool.

Received for publication 15 July 1976 and cholinergic drugs, and tolbutamide (Raab et al., 1958; Weissler et al., 1965; Harris et al., 1967; Shapiro et al., 1970; Crockett et al., 1973). Martin et al. (1971) have shown that systolic time intervals correlate well with internal measurements of left ventricular function.

\section{Patients and methods}

Nineteen untreated male patients attending the diabetic clinic for the first time were studied. Nine patients were subsequently managed with diet alone and 10 with diet and a sulphonylurea drug. The severity of the diabetes determined treatment. A random plasma sugar level greater than $14 \mathrm{mmol} / 1$ $(252 \mathrm{mg} / 100 \mathrm{ml})$ usually indicated the need for hypoglycaemic compounds. Each individual was seen again 1 month and 3 months after starting treatment. At each attendance the plasma sugar concentration, weight, and systolic time intervals were measured. Recordings of the full electrocardiogram and the blood pressure were made on every patient at the first visit. Systolic time intervals were obtained by using a Mingograph 3-channel recorder (Elema-Schonander) modified to reproduce simultaneously the electrocardiogram, phonocardiogram, and carotid pulse wave at a paper speed of $100 \mathrm{~mm} / \mathrm{s}$. From these tracings were derived the $\mathrm{QS}_{2}$ interval-from the start of the QRS complex to the start of the aortic second sound, the left ventricular ejection time (LVET)-from the start of the upstroke of the carotid pulse to the incisura, and the 
pre-ejection period (PEP) which is the difference between the $\mathrm{QS}_{2}$ and LVET. The mean values of 10 complexes were obtained for each measurement. The $\mathrm{QS}_{2}$, LVET, and PEP results were then corrected for heart rate using the regression equations of Weissler et al. (1969). The PEP/LVET ratio was calculated using the uncorrected values of PEP and LVET.

Seven patients in the diet group and 8 of those who needed an oral hypoglycaemic drug had normal electrocardiograms. Two patients in the drug treated group and 2 controlled by diet showed ischaemic ST depression.

Of those in the sulphonylurea drug group 7 patients received glibenclamide and 3 tolazamide. The dosages of the drugs were in the therapeutic range in each case. Three patients on glibenclamide received $10 \mathrm{mg}$ daily and 2 were on $5 \mathrm{mg}$ a day. The doses in the remaining 2 patients on this drug were $2.5 \mathrm{mg}$ and $20 \mathrm{mg}$, respectively. In the tolazamide treatment group 1 patient received $250 \mathrm{mg}$ daily while the remaining 2 were on $350 \mathrm{mg}$ daily. No patient in the study was given any other medication.

The mean age of each group was similar.

Twenty-seven ambulant male volunteers with clinically normal hearts and blood pressures were investigated in an identical manner to provide control data. They all had normal electrocardiograms, plasma sugar concentrations, and their mean age and weight were similar to those of the diabetic groups.

To avoid any errors resulting from a possible diurnal variation of systolic time intervals, all measurements in the 19 diabetics and 27 control subjects were made between $14 \cdot 00$ and $16 \cdot 00$ hours.

\section{Results}

Tables 1 and 2 show the results.

The resting heart rate before treatment was greater among the more hyperglycaemic diabetic patients needing both sulphonylurea drugs and dietary restriction, when compared with the control subjects $(P<0.01)$. The difference was still apparent 1 month after starting drug therapy but was no longer significant at 3 months. The heart rate of diabetic patients managed with dietary restriction alone showed no significant difference from the other two groups either before therapy or at the subsequent visits.

There was a small but significant shortening of the rate corrected $\mathrm{QS}_{2}$ interval $\left(\mathrm{QS}_{2} \mathrm{I}\right)$ in the drug treated patients before therapy when compared with the control group $(P<0.001)$. There was a gradual lengthening of the $\mathrm{QS}_{2} \mathrm{I}$ at succeeding visits. It remained less than the control value at 1 month $(P<0.02)$ but finally no difference was shown between the control subjects and the drugtreated diabetics (Fig. 1).

The diet group, however, behaved differently. There was no abnormality of the $\mathrm{QS}_{2} \mathrm{I}$ when the three measurements were compared with each other and with those of the control group. However, a lengthening of the $\mathrm{QS}_{2} \mathrm{I}$ occurred within the diet group when paired differences were analysed $(\mathrm{P}<0.05)$.

Although before treatment significant shortening of the rate corrected PEP (PEPI) was absent when the two groups of diabetics were considered separately the PEPI of all 19 diabetics was $113 \mathrm{~ms}$ (standard deviation 15.9). This was less than the control value $(P<0.05)$. During the study lengthening of the PEPI occurred as shown by a paired ' $t$ ' test $(P<0.02)$ and at the final visit the PEPI of diabetics and control subjects was similar. Before treatment there was shortening of the rate corrected LVET (LVETI) in the drug treated group when compared with the diet and control groups $(\mathrm{P}<0.05$ and $P<0.02$, respectively). During the study lengthening of the LVETI occurred within the

Table 1 Data for diabetic patients at each visit compared with those of control group ( $\pm 1 S D)$

\begin{tabular}{|c|c|c|c|c|c|c|c|}
\hline & $\begin{array}{l}\text { Diet group } \\
\text { 1st visit } \\
\text { (9) }\end{array}$ & $\begin{array}{l}2 n d \text { visit } \\
\text { (9) }\end{array}$ & $\begin{array}{l}\text { 3rd visit } \\
\text { (9) }\end{array}$ & $\begin{array}{l}\text { Tablet grou } \\
\text { 1st visit } \\
\text { (10) }\end{array}$ & $\begin{array}{l}\text { 2nd visit } \\
\text { (10) }\end{array}$ & $\begin{array}{l}\text { 3rd visit } \\
\text { (10) }\end{array}$ & $\begin{array}{l}\text { Control } \\
\text { group } \\
(27)\end{array}$ \\
\hline Age (y) & $\begin{array}{r}53.6 \\
\pm 13.1\end{array}$ & - & - & $\begin{array}{l}52.4 \\
\pm 6.8\end{array}$ & - & - & $\begin{array}{r}50.9 \\
\pm 9.4\end{array}$ \\
\hline Weight (kg) & $\begin{array}{r}82.6 \\
\pm 15.0\end{array}$ & $\begin{array}{r}82.0 \\
+14.9\end{array}$ & $\begin{array}{r}78.8 \\
\pm 13.9\end{array}$ & $\begin{array}{r}74.7 \\
+10.1\end{array}$ & $\begin{array}{c}74.5 \\
\pm 11.5\end{array}$ & $\begin{array}{r}74.6 \\
+13.0\end{array}$ & $\begin{array}{r}75.3 \\
+13.1\end{array}$ \\
\hline Heart rate $(b / \mathrm{min})$ & $\begin{array}{r}72.6 \\
\pm 10.3\end{array}$ & $\begin{array}{r}75.2 \\
\pm 11.6\end{array}$ & $\begin{array}{r}73.6 \\
\pm 10.5\end{array}$ & $\begin{array}{r}81.5 \\
\pm 11.2\end{array}$ & $\begin{array}{c}80.9 \\
\pm 10.3\end{array}$ & $\begin{array}{r}76.5 \\
\pm 8.5\end{array}$ & $\begin{array}{r}68.8 \\
\pm 11.0\end{array}$ \\
\hline Systolic blood pressure (mmHg) & $\begin{array}{c}141 \\
\pm 13.6\end{array}$ & & & $\begin{array}{c}151 \\
\pm 14.5\end{array}$ & & & $\begin{array}{l}132 \\
\pm 16.8\end{array}$ \\
\hline Diastolic blood pressure (mmHg) & $\begin{array}{r}84.4 \\
\pm 7 \cdot 7\end{array}$ & & & $\begin{array}{r}89.5 \\
+10.1\end{array}$ & & & $\begin{array}{r}81.9 \\
+12.3\end{array}$ \\
\hline Plasma sugar concentration (mmol/l) & $\begin{array}{r}11.0 \\
\pm 3.1\end{array}$ & $\begin{array}{r}8 \cdot 2 \\
\pm 2 \cdot 1\end{array}$ & $\begin{array}{r}8.2 \\
\pm 1.5\end{array}$ & $\begin{array}{r}18.6 \\
\pm 3.0\end{array}$ & $\begin{array}{r}8.4 \\
\pm 2.0\end{array}$ & $\begin{array}{r}6.8 \\
\pm 2.3\end{array}$ & $\begin{array}{r}5 \cdot 7 \\
\pm 1 \cdot 1\end{array}$ \\
\hline
\end{tabular}


Table 2 Mean corrected $Q S_{2}$ interval, corrected LVET, corrected PEP, and PEP/LVET in control group and at each visit $( \pm 1 S D)$

\begin{tabular}{|c|c|c|c|c|c|c|c|}
\hline & $\begin{array}{l}\text { Diet group } \\
\text { 1st visit } \\
\text { (9) }\end{array}$ & (9) visit & $\begin{array}{l}\text { 3rd visit } \\
\text { (9) }\end{array}$ & $\begin{array}{l}\text { Tablet grout } \\
\text { 1st visit } \\
\text { (10) }\end{array}$ & $\begin{array}{l}\text { 2nd visit } \\
(10)\end{array}$ & $\begin{array}{l}\text { 3rd visit } \\
\text { (10) }\end{array}$ & $\begin{array}{l}\text { Control } \\
\text { group } \\
\text { (27) }\end{array}$ \\
\hline $\begin{array}{l}\text { Corrected } \mathrm{QS}_{\mathbf{2}} \text { interval }\left(\mathrm{QS}_{\mathbf{2}} \mathrm{I}\right) \\
\text { Corrected PEP (PEPI) } \\
\text { Corrected LVET (LVETI) } \\
\text { PEP/LVET ratio }\end{array}$ & $\begin{array}{c}523 \\
\pm 15.6 \\
113.9 \\
\pm 13.2 \\
409.1 \\
\pm 18.4 \\
0.30 \\
\pm 0.061\end{array}$ & $\begin{array}{c}526.5 \\
\pm 17.2 \\
117.9 \\
\pm 8.7 \\
409.3 \\
\pm 16.7 \\
0.31 \\
\pm 0.039\end{array}$ & $\begin{array}{c}533.4 \\
\pm 12.5 \\
125 \cdot 1 \\
\pm 14.6 \\
408 \cdot 2 \\
\pm 18 \cdot 2 \\
0.34 \\
\pm 0.071\end{array}$ & $\begin{array}{c}503.3 \\
\pm 25.9 \\
112.3 \\
\pm 18.7 \\
391.3 \\
\pm 13.5 \\
0.32 \\
\pm 0.075\end{array}$ & $\begin{array}{c}513.6 \\
\pm 20.1 \\
114.3 \\
\pm 15.1 \\
399.4 \\
\pm 14.1 \\
0.31 \\
\pm 0.061\end{array}$ & $\begin{array}{c}529.9 \\
\pm 17.6 \\
118.8 \\
\pm 21.2 \\
411.3 \\
\pm 9.4 \\
0.31 \\
\pm 0.079\end{array}$ & $\begin{array}{r}527.8 \\
\pm 12.2 \\
122.5 \\
\pm 14.6 \\
405.4 \\
\pm 14.6 \\
0.33 \\
\pm 0.06\end{array}$ \\
\hline
\end{tabular}

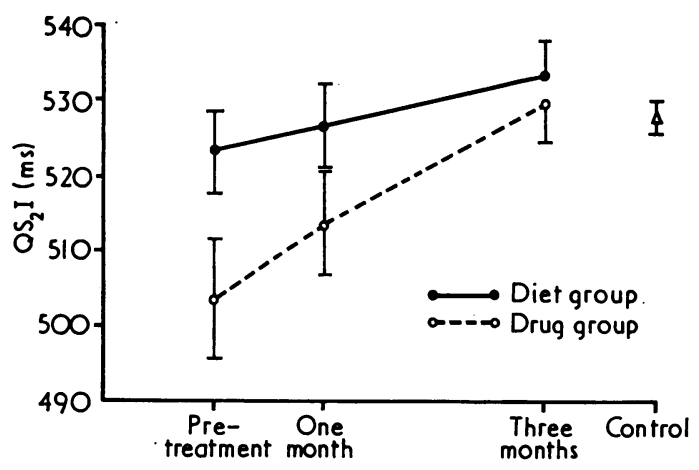

Fig. 1 Mean corrected $Q S_{2}$ interval $\left(Q S_{2} I\right) \pm 1 S E M$ in the two diabetic treatment groups with control values for comparison.

tablet group $(\mathrm{P}<0.001)$. The patients on dietary control showed no difference either when considering the group as a whole or when paired differences were analysed (Fig. 2).

The PEP/LVET ratio showed no significant deviation from control values in any of the diabetic patients throughout the study.

There were high plasma sugar concentrations in both the diabetic groups at the first visit when compared with the control values $(P<0.0005)$. The levels were greater in the drug treated patients, as therapy was determined by the initial severity of the diabetes. After 1 month the plasma sugar concentrations in both diabetic groups had fallen but were still higher than those of the control series $(P<0.0005)$. At the final visit the mean plasma sugar level of the diet group remained greater than the control values $(P<0.005)$ but that of the drug treated patients occupied an intermediate position and was not statistically different from those of the other two groups.

Although the mean weights of the patients were similar at each visit a paired ' $t$ ' test showed a reduction in weight during the study in the diet

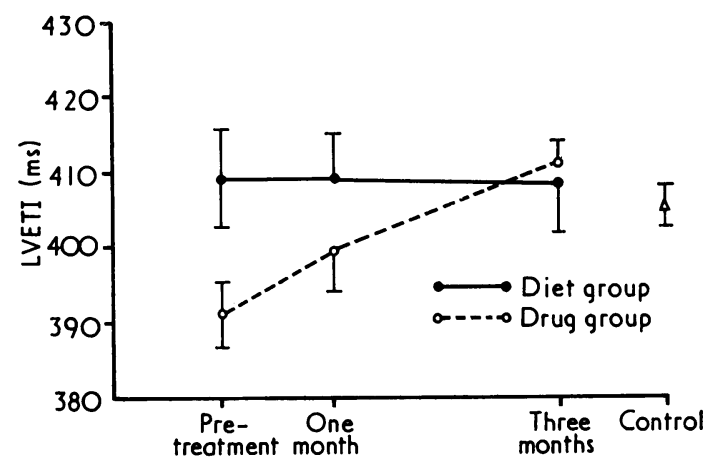

Fig. 2 Mean corrected left ventricular ejection time (LVETI) $\pm 1 S E M$ in the two diabetic treatment groups with control values for comparison.

treated group $(P<0.05)$ but not in the individuals on oral hypoglycaemic drugs.

Blood pressure was measured at the initial visit. The systolic pressure was significantly higher in the group needing sulphonylurea drugs when compared with the control values $(P<0.01)$, but the patients requiring diet alone showed no significant difference from the other two groups. The diastolic blood pressure was similar in all three groups.

\section{Discussion}

The small but significant cardiovascular changes shown among diabetic patients appeared to be related to the severity of the underlying hyperglycaemia in that they were present to their greatest extent in diabetic patients with sugar levels high enough to require sulphonylurea drugs in addition to dietary restriction. Under the influence of therapy there was a gradual return to control values of both heart rate and systolic time intervals accompanying the reduction in plasma sugar though the biochemical improvement was somewhat faster than the haemodynamic. 
One possible explanation of the observed cardiovascular changes could be an increased adrenergic stimulus more obvious in the hyperglycaemic diabetic. Adrenaline produces a reduction of PEP and $\mathrm{QS}_{2}$ (Raab et al., 1958; Harris et al., 1967; Martin et al., 1971). Raab et al. (1958) have also found a shortening of $\mathrm{QS}_{2}$ (total electromechanical systole) and LVET with adrenaline. Such a mechanism has been suggested to explain the shortening of the $\mathrm{QS}_{2}$ interval after myocardial infarction (Lewis et al., 1972). Certainly a rise in catecholamines, notably noradrenaline, is known to occur when diabetes is out of control (Christensen, 1974). None the less, at the second visit when satisfactory control of diabetes was obtained a fall in circulating catecholamines would have been expected to occur, and hence a return of the systolic time intervals to normal, whereas systolic time intervals were still significantly shortened.

Another possible mechanism which may explain the reduction in the LVETI is lipid deposition within the myocardial cells reducing the compliance and thus the stroke volume. Animal studies have shown cholesterol and triglyceride deposition within the myocardium in alloxan-induced diabetes (Regan et al., 1974). If excess lipids were present within the myocardium, a situation similar to a restrictive cardiomyopathy would develop. The LVET has been shown to shorten in this type of cardiomyopathy. However, lengthening of the PEP and increase in the PEP/LVET ratio also occur as would be expected in any situation where myocardial contractility is reduced (Khullar and Lewis 1976; Ghose et al., 1976). Such a mechanism would not, therefore, account for the initial shortening of PEP encountered in the present state.

Relatively high systolic blood pressure among the more severely hyperglycaemic group would tend to lengthen rather than shorten the LVET (Braunwald et al., 1958; Shaver et al., 1968), and the diastolic pressures were similar in all three groups of patients.

The purpose of the study was to examine the possibility that sulphonylurea drugs may have an overall positive inotropic effect on the myocardium when used in the management of diabetes. Our results appear to show that this is not so. The drugtreated group had a significant lengthening of LVETI during the period of treatment towards the values obtained among the control subjects and all diabetics showed an increase in PEPI. This is the reverse of the shortening of these time intervals with positive inotropic drugs such as cardiac glycosides (Weissler et al., 1965; Shapiro et al., 1970).

It seems likely that the changes in cardiovascular behaviour with control of diabetes are too complex to ascribe any result to a single intervention such as drug administration. If the changes observed in this study are the result of the withdrawal of an increased adrenergic stimulus to the heart which occurs in the untreated state, this may have clinical significance and could explain the improvement in angina which can occur after administration of the sulphonylurea (Singh and Bardhan, 1959). At all events we have found nothing to suggest that the particular sulphonylurea drugs studied produce a positive inotropic effect potentially hazardous in the management of patients with diabetes.

C. A Sykes was a Research Fellow in receipt of a United Birmingham Hospitals Endowment Fund Research Fellowship.

\section{References}

Braunwald, E., Sarnoff, S. J., and Stainsby, W. N. (1958). Determinants of duration and mean rate of ventricular ejection. Circulation Research, 6, 319-325.

Christensen, N. J. (1974). Plasma norepinephrine and epinephrine in untreated diabetics, during fasting and after insulin administration. Diabetes, 23, 1-8.

Crass, M. F., Spanheimer, R. G., Stone, D. B., and Brown, R. J. (1973). Tolbutamide-induced inotropic responses in the perfused working heart. Effects of albumin. Proceedings of the Society for Experimental Biology and Medicine, 142, 861-866.

Crockett, S., Marsh, D., Lewis, R., and Tzagournis, $M$. (1973). Inotropic effects of tolbutamide in intact man (abstract). Diabetes, 22, Suppl. 1, 293.

Crockett, S., Marsh, D., Lewis, R., and Tzagournis, M. (1974). Lack of cardiac inotropic effect of tolbutamide in intact man. Metabolism, 23, 763-769.

Ghose, J. C., Mitra, S. K., and Chhetri, M. K. (1976). Systolic time intervals in the differential diagnosis of constrictive pericarditis and cardiomyopathy. British Heart fournal, 38, 47-50.

Harris, W. S., Schoenfeld, C. D., and Weissler, A. M. (1967). Effects of adrenergic receptor activation and blockade on the systolic pre-ejection period, heart rate and arterial pressure in man. Fournal of Clinical Investigation, 46, 1704-1714.

Hildner, F. J., Ramaswamy, K., Javier, R. P., Lasseter, K. C., Samet, P., and Yeh, B. K. (1971). Hemodynamic effects of tolbutamide in man. Circulation, 43 and 44, Suppl. 2, 178.

Khullar, S., and Lewis, R. P. (1976). Usefulness of systolic time intervals in differential diagnosis of constrictive pericarditis and restrictive cardiomyopathy. British Heart fournal, 38, 43-46.

Klimt, C. R., Knatterud, G. L., Meinert, C. L., and Prout, T. E. (1970). A study of the effects of hypoglycemic agents on vascular complications in patients with adult onset diabetes. Diabetes, 19, Suppl. 2, 747-830.

Lasseter, K. C., Levey, G. A., Palmer, R. F., and McCarthy, J. S. (1972). Effect of sulphonylurea drugs on rabbit myocardial contractility, canine purkinje fibre automaticity, and adenyl cyclase activity from rabbit and human hearts. fournal of Clinical Investigation, 51, 2429-2434.

Lewis, R. P., Boudoulas, H., Forester, W. R., and Weissler, A. M. (1972). Shortening of electromechanical systole as a manifestation of excessive adrenergic stimulation in acute myocardial infarction. Circulation, 46, 856-862. 
Martin, C. E., Shaver, J. A., Thompson, M. E., Reddy, P. S., and Leonard, J. J. (1971). Direct correlation of external systolic time intervals with internal indices of left ventricular function in man. Circulation, 44, 419-431.

Palmer, R. F., Lasseter, K. C., and McCarthy, J. (1971). Tolbutamide; an inotropic effect on rabbit atria. Lancet, 1, 604.

Raab, W., De Paula e Silva, P., and Starcheska, Y. K. (1958). Adrenergic and cholinergic influences on the dynamic cycle of the normal human heart. Cardiologia, 33, 350-364.

Regan, T. J., Ettinger, P. O., Khan, M. I., Jesrani, M. U., Lyons, M. M., Oldewurtel, H. A., and Weber, M. (1974). Altered myocardial function and metabolism in chronic diabetes mellitus without ischemia in dogs. Circulation Research, 35, 222-237.

Shapiro, W., Narahara, K., and Taubert, K. (1970). Relationship of plasma digitoxin and digoxin to cardiac response following intravenous digitalization in man. Circulation, 42, 1065-1072.

Shaver, J. A., Kroetz, F. W., Leonard, J. J., and Paley, H. W. (1968). The effect of steady-state increases in systemic arterial pressure on the duration of left ventricular ejection time. Fournal of Clinical Investigation, 47, 217-230.

Singh, I., and Bardhan, P. N. (1959). Tolbutamide in the treatment of angina pectoris. Lancet, 2, 1141-1142.

Weissler, A. M., Harris, W. S., and Schoenfeld, C. D. (1969). Bedside technics for the evaluation of ventricular function in man. American fournal of Cardiology, 23, 577-583.

Weissler, A. M., Kamen, A. R., Bornstein, R. S., Schoenfeld, C. D., and Cohen, S. (1965). The effect of deslanoside on the duration of the phases of ventricular systole in man. American fournal of Cardiology, 15, 153-161.

Young, J. L., Jr., Burr, I. M., Perry, J. M., Nelson, J. H., and Nies, A. S. (1975). Inotropic effects of tolbutamide in man. American Heart fournal, 89, 189-194.

Requests for reprints to Dr. C. A. Sykes, Regional Cardiac Centre, Sefton General Hospital, Smithdown Road, Liverpool L15 2HE. 